\title{
Avaliação da Composição de Cortes Comerciais, Componentes Corporais e Órgãos Internos de Cordeiros Confinados e Alimentados com Dejetos de Suínos
}

\author{
Marcus Vinícius Morais de Oliveira ${ }^{1}$, Juan Ramón Olalquiaga Pérez ${ }^{2}$, Eduardo Luis Alves ${ }^{3}$, \\ Alessandra Rodrigues Vieira Martins ${ }^{3}$, Rogério de Paula Lana ${ }^{4}$
}

RESUMO - Foram utilizados 21 cordeiros, nove da raça Bergamácia e 12 Santa Inês, os quais permaneceram confinados individualmente por 75 dias, sendo alimentados com dietas contendo $24 \%$ de dejetos de suínos, na forma de biju (dejeto obtido pela raspagem e varredura do piso das baias de crescimento e terminação) ou DPS - dejeto peneirado seco (constituído pela parte sólida do material contido na lâmina d'água e da água de lavagem das baias, obtida através de peneiras de malha fina). Os dejetos de suínos não influenciaram a porcentagem de músculo, gordura e osso dos cortes analisados. Os cordeiros da raça Santa Inês apresentaram maior quantidade de músculo no pernil e maior área olho de lombo que os Bergamácia. Estes, no entanto, apresentaram maior proporção de gordura na paleta quando os cortes foram expressos em \% do peso de cada corte. A dieta controle também propiciou maior área olho de lombo que a dieta com biju. Uma maior proporção de intestino delgado, expresso em \% do peso aparelho digestivo, foi verificada nos animais que receberam a dieta controle em relação aos que receberam DPS. Os cordeiros Santa Inês apresentaram maior peso da traquéia, quando esta variável foi expressa em $\mathrm{kg}$ do órgão e em \% do peso vazio; já os Bergamácia apresentaram maior quantidade de pele, quando esta foi expressa como \% do peso vazio. Conclui-se que a utilização de dejetos de suínos não afeta a composição dos cortes comerciais, os pesos dos componentes corporais e os órgãos internos.

Palavras-chave: Bergamácia, confinamento, ovinos, rendimento, Santa Inês

\section{Evaluation of Commercial Joint, Body Components and Internal Organs of Confined Lambs and Fed with Swine Wastes}

\begin{abstract}
Twenty-one lambs were used, nine of the Bergamácia and 12 Santa Inês breed, were confined individually for 75 days, and fed diets containing $24 \%$ of swine wastes, in the form of biju (obtained by the scratching and sweeping of the floor of the growth and termination stalls) or DSW - dry sifted wastes (constituted by the solid part of the material contained of the water of wash of the stalls, obtained through sieves of fine mesh). There was no diet effect in the percentage of muscle, fat and bone of the analyzed cuts. The Santa Inês lambs showed larger amount of muscle in the ham and a larger loin eye area that Bergamácia; these however showed a larger fat proportion in the whole shoulder when the joints were expressed in $\%$ of the weight of each joint. The diet controls also propitiated one larger loin eye area that the diet with biju. A larger proportion of small intestine, expressed in \% weight of the digestive system, was verified in the animals fed with the diets controls in relation those fed whit DPS. The lambs of the Santa Inês breed showed larger weight of the windpipe, when this parameter was expressed in $\mathrm{kg}$ and in $\%$ of the empty weight; already the Bergamácia presented larger amount of skin, when this was expressed as \% of the empty weight. It is concluded that the use of swine wastes doesn't affect the composition of the commercial joints, weights of body components and internal organs.
\end{abstract}

Key Words: Bergamacia, confinement, dressing, Santa Inês, sheep

\section{Introdução}

A terminação de cordeiros em confinamento apresenta uma série de benefícios, como menor mortalidade dos animais devido à menor incidência de verminoses e maior controle da parte nutricional; isso proporciona abate precoce e carcaças com alta qualidade, o que se reflete em melhor preço pago pelo mercado consumidor e garante ao produtor retorno mais rápido do capital investido. No entanto, as maiores desvantagens se encontram nos altos custos de produção, principalmente na alimentação, que constitui um fator determinante no aspecto financeiro.

Como forma de reduzir os custos com a alimentação, novas fontes alternativas de alimento estão sendo estudadas, destacando-se dentre elas os dejetos

\footnotetext{
${ }^{1}$ Estudante de Doutorado - Departamento de Zootecnia / UFV. Endereço: Avenida Santa Rita, n. 110 apto 201 - Centro, Viçosa-MG CEP 36.570.000. E.mail: marcusvm@alunos.ufv.br

2 Professor Titular - Departamento de Zootecnia/UFLA. E.mail: jroperez@ufla.br

${ }^{3}$ Mestre em Zootecnia.

${ }^{4}$ Professor - Departamento de Zootecnia/UFV.
} 
de suínos (Rodrigues et al., 1996). Isso se deve ao crescente aumento das criações intensivas de suínos, que geram a produção de grandes volumes de dejetos, os quais, se não forem tratados ou utilizados adequadamente, acarretam sérios problemas ao meio ambiente. Um aspecto positivo na utilização de dejetos de suínos na alimentação de ruminantes deve-se principalmente ao fato de parte da proteína bruta desses resíduos estar na forma não-protéica, como, por exemplo, ácido úrico, uréia e amônia. Assim, os microrganismos do rúmen transformam esses compostos em proteína microbiana de alto valor biológico, sendo esta posteriormente digerida e incorporada (Oliveira, 1993).

No Brasil, a comercialização de ovinos é feita em observações no animal, sendo o peso vivo o principal parâmetro adotado. No entanto, para o mercado consumidor, o mais importante é o rendimento das partes comestíveis e sua composição, expressa em porcentagem de músculo, gordura e osso. A qualidade da carne, assim como o rendimento da carcaça, também depende de um conjunto de fatores relacionados ao animal, como: idade, sexo, raça e pesos de abate, do aparelho digestivo e órgãos internos; relativos ao meio, como: alimentação e condições de manejo; e relativos à carcaça propriamente dita, como: peso e conformação da carcaça, área de olho de lombo, entre outros (Figueiró, 1979). Entretanto, poucos estudos têm sido realizados em relação aos componentes e aos órgãos corporais; possivelmente, esse reduzido interesse se deva ao fato de estas variáveis não fazerem parte da carcaça comercial. Todavia, pesquisas nesse ramo devem ser realizadas, já que os órgãos internos, através de um processamento adequado, podem se tornar valiosos subprodutos da indústria da carne, além de contribuírem para estudos biológicos, nutricionais e medicinais (Kirton et al., 1995).

Assim, objetivou-se estudar os pesos dos principais cortes comerciais e sua respectiva composição de músculo, gordura e osso; mensurar o músculo longissimus dorsi; estudar os componentes corporais e órgãos internos; e determinar as possíveis influências da utilização de dejetos de suínos na ração de cordeiros das raças Bergamácia e Santa Inês.

\section{Material e Métodos}

O experimento foi realizado no Departamento de Zootecnia da Universidade Federal de Lavras, em Lavras - MG. Foram utilizados 21 cordeiros machos inteiros, sendo 12 da raça Santa Inês e 9 da raça Bergamácia, com idade e peso vivo médio de 135 dias e $30 \mathrm{~kg}$, respectivamente. Antes de iniciar o experimento, todos os cordeiros receberam tratamentos contra ecto e endoparasitas, sendo posteriormente confinados em gaiolas individuais de estrutura metálica, montadas sob um galpão coberto, providas de cocho e bebedouro.

Foi realizado um período pré-experimental de 15 dias, de modo que permitisse a adaptação dos cordeiros às condições de manejo e alimentação. O período experimental teve duração de 75 dias. Os cordeiros foram alimentados à vontade, com uma ração contendo $20 \%$ de feno de aveia e $80 \%$ de concentrado. Dos $80 \%$ do concentrado, $24 \%$ eram de dejetos de suínos, na forma de biju (dejeto obtido através da raspagem e varredura do piso das baias de crescimento e terminação de suínos), sendo composto por fezes, urina, ração desperdiçada, pêlos e poeiras decorrentes do processo criatório; depois de retirados do piso, os dejetos são secos ao sol e posteriormente moídos; ou de DPS - dejeto peneirado seco ao sol (dejeto obtido através de um processo que envolve a separação dos dejetos contidos na lâmina d'água e na água da lavagem das instalações), sendo composto por fezes, urina, pêlos, resíduos de ração, água desperdiçada dos bebedouros e água utilizada no processo de higienização. Esta técnica baseia-se no transporte dos dejetos por meio da água corrente nas canaletas que se localizam na parte inferior das baias, e, desse modo, os dejetos saem das baias com a lavagem e vão para um tanque de estocagem, de onde são periodicamente retirados para a separação das partes sólida e líquida, por meio de um processo de peneiramento (peneiras vibratórias) e prensamento; posteriormente, a parte sólida é seca ao sol e moída e a fração líquida é utilizada na irrigação de culturas. As dietas foram formuladas com teores protéicos semelhantes, cerca de $15 \%$ de PB, com base na MS, e em média possuíam $2.544 \mathrm{kcal} / \mathrm{kg}$ de energia digestível, 1,34 e $0,64 \%$ na MS de cálcio e fósforo, respectivamente (Tabela 1); os teores de MS, PB, EE, FDN, Ca e P, expressos em $\%$ da MS, para o biju foram de 83,$7 ; 24,3$; 7,$9 ; 22,5 ; 0,34$; e 0,32 ; e para o DPS, de 83,$6 ; 11,5 ; 2,5$; 73,$3 ; 1,90$; e 1,09 , respectivamente.

$\mathrm{O}$ abate foi realizado quando os animais completavam 210 dias de idade e $45 \mathrm{~kg}$ de peso vivo em média; antes de serem sacrificados, os cordeiros permaneceram em jejum de sólidos por um período de 15 horas. Após o sacrifício dos animais, realizou-se a

R. Bras. Zootec., v.31, n.3, p.1459-1468, 2002 (suplemento) 
Tabela 1 - Composição percentual dos ingredientes e teores de proteína bruta e de energia digestível das dietas

Table 1 - Percentage composition of ingredients and crude protein and digestible energy of the diets

\begin{tabular}{|c|c|c|c|}
\hline \multirow[t]{2}{*}{$\begin{array}{l}\text { Tratamentos } \\
\text { Treatments }\end{array}$} & \multicolumn{3}{|c|}{$\begin{array}{l}\text { Ingredientes } \\
\text { Ingredient }\end{array}$} \\
\hline & $\begin{array}{l}\text { T1- Controle } \\
\text { T1-Control }\end{array}$ & $\begin{array}{l}\text { T2-Biju } \\
\text { T2-Biju }\end{array}$ & $\begin{array}{l}\text { T3-DPS } \\
\text { T3- DSW }\end{array}$ \\
\hline $\begin{array}{l}\text { Feno de aveia }(\%) \\
\text { Oats hay (\%) }\end{array}$ & 20,00 & 20,00 & 20,00 \\
\hline Milho grão (\%) & 66,40 & 52,80 & 44,00 \\
\hline $\begin{array}{l}\text { Corn grain }(\%) \\
\text { Farelo de soja }(\%) \\
\text { Soybean meal }(\%)\end{array}$ & 10,40 & - & 8,80 \\
\hline $\begin{array}{l}\text { Farinha carne e ossos (\%) } \\
\text { Meat and bones meal (\%) }\end{array}$ & 1,60 & 1,60 & 1,60 \\
\hline $\begin{array}{l}\text { Dejetos suínos - Biju (\%) } \\
\text { Swine wastes - Biju (\%) }\end{array}$ & - & 24,00 & - \\
\hline $\begin{array}{l}\text { Dejetos suínos - DPS (\%) } \\
\text { Swine wastes - DSW (\%) }\end{array}$ & - & - & 24,00 \\
\hline $\begin{array}{l}\text { Premix mineral }(\%)^{1} \\
\text { Premix mineral }(\%)^{1}\end{array}$ & 1,20 & 1,20 & 1,20 \\
\hline $\begin{array}{l}\text { Sal (\%) } \\
\text { Salt (\%) }\end{array}$ & 0,40 & 0,40 & 0,40 \\
\hline $\begin{array}{l}\text { Total }(\%) \\
\text { Total }(\%)\end{array}$ & 100,00 & 100,00 & 100,00 \\
\hline $\begin{array}{l}\text { Proteína bruta (\% na MS) } \\
\text { Crude protein (\% in DM) }\end{array}$ & 15,01 & 15,41 & 14,75 \\
\hline $\begin{array}{l}\text { Energia digestível }(\mathrm{kcal} / \mathrm{kg}) \\
\text { Digestible energy }(\mathrm{kcal} / \mathrm{kg})\end{array}$ & 2.637 & 2.588 & 2.408 \\
\hline $\begin{array}{l}\text { Cálcio (\% na MS) } \\
\text { Calcium }(\% \text { in } D M)\end{array}$ & 1,20 & 1,47 & 1,36 \\
\hline $\begin{array}{l}\text { Fósforo (\% na MS) } \\
\text { Phosphorus (\% in DM) }\end{array}$ & 0,54 & 0,69 & 0,68 \\
\hline
\end{tabular}

evisceração, sendo os órgãos e os componentes corporais externos pesados posteriormente. Assim, determinou-se individualmente o peso, em $\mathrm{kg}$, dos órgãos do aparelho digestivo (rúmen/retículo, omaso, abomaso, intestino delgado e intestino grosso), de alguns órgãos internos (traquéia, pulmão, coração, fígado e baço), da gordura visceral (omental e mesentérica) e de alguns componentes corporais externos, como a cabeça, os pés/canela e a pele. Já as carcaças, pesando em média $24,1 \mathrm{~kg}$, foram resfriadas em câmara frigorífica por 24 horas a uma temperatura de $2^{\circ} \mathrm{C}$; posteriormente, retirou-se o pescoço da carcaça e essa foi seccionada acompanhando a linha central da coluna vertebral. A metade esquerda foi subdividida nos seguintes cortes comerciais: paleta, pernil, lombo e costela, os quais foram pesados, embalados em sacos plásticos e congelados em freezer para posterior dessecação, obtendo-se assim os pesos de músculo, gordura e osso de cada corte.

Antes da dissecação do lombo, determinou-se a área transversal do músculo longissimus dorsi, entre a última vértebra torácica e a primeira lombar, sendo traçado o seu perfil em papel vegetal e posteriormente mensurada sua área, em milímetros quadrados, utilizando-se um planímetro, e sua maior largura e seu maior comprimento, em centímetros, utilizando-se um escalímetro (Figura 1).

O delineamento utilizado foi em blocos casualizados em fatorial 2 × 3 (duas raças e três dietas). Os dados foram submetidos à análise estatística pelo programa SAS (1990), através do procedimento GLM, utilizando-se o peso vazio como covariável. As médias dos dados foram comparadas pelos testes $\mathrm{F}$ e de Tukey em nível de $5 \%$. 
B

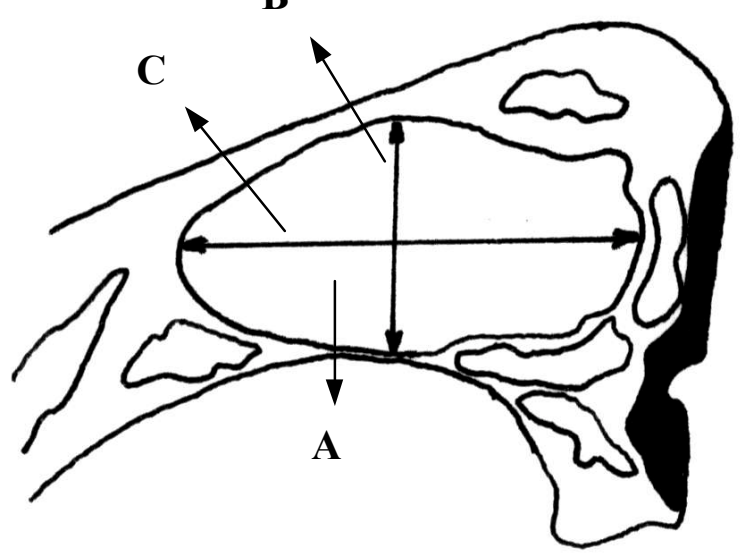

Figura 1- Esquema das mensurações feitas no músculo longissimus dorsi: A) área de olho lombo, B) largura e C) comprimento.

Figure 1 - Scheme of the measure done in the muscle longissimus dorsi: A) loin eye area, B) width and C) length.

\section{Resultados e Discussão}

Na Tabela 2 são mostrados os pesos, em kg, dos principais cortes comerciais (paleta, pernil, lombo e costela), não sendo verificada nenhuma influência das dietas ou das raças nos pesos dos respectivos cortes comerciais.

Murphy et al. (1994), ao abaterem cordeiros cruzados com cerca de $48 \mathrm{~kg}$ de peso vivo, verificaram pesos de alguns cortes comerciais, como a perna, de 3,756 kg, o lombo, de 1,961 kg, e a paleta, de $2,949 \mathrm{~kg}$, sendo todos os cortes mais pesados que os encontrados neste experimento. Já Latif \& Owen (1980) encontraram pesos da perna, do lombo e da paleta de 2,08; 0,99; e 1,71 kg, respectivamente, para cordeiros das raças Suffolk e Texel abatidos com cerca de $36 \mathrm{~kg}$ de peso vivo e 119 dias de idade.

Segundo Maynard et al. (1984), a ordem cronológica de desenvolvimento dos tecidos se dá inicialmente com os ossos, sendo seguido posteriormente pelos tecidos musculares e adiposos. Assim, a interpretação da relação entre estes tecidos é fundamental para se conhecer a qualidade da carcaça que será comercializada. Esses dados também poderão auxiliar na determinação do ponto ideal de abate, ou seja, a idade em que o cordeiro estará depositando a maior quantidade de carne, desde que se abatam os animais em diversos pesos e/ou idade.

$\mathrm{Na}$ Tabela 3 são verificados os pesos, em $\mathrm{kg}$, de músculo, gordura e osso dos principais cortes comerciais. Com exceção da raça Santa Inês, que apresentou maior peso de músculo para o corte do pernil, não se observou nenhum efeito das dietas ou das raças nos demais parâmetros. Verificou-se, no entanto, maior desenvolvimento e rendimento muscular do corte pernil, demonstrando ser este o mais nobre do ovino. Isso também foi enfatizado por Figueiró (1979), o qual determinou que a perna era a parte da carcaça que mais contribuía para o peso e rendimento comestível desta.

Murphy et al. (1994) verificaram a seguinte composição de músculo, gordura e osso, respectivamente, dos seguintes cortes comerciais: perna $(2,137,0,980$ e $0,631 \mathrm{~kg})$; lombo $(0,705,0,998$ e $0,206 \mathrm{~kg})$ e paleta $(1,528,0,854$ e 0,562 kg). Já Khandekar et al. (1965), ao trabalharem com cordeiros cruzados abatidos com cerca de $35 \mathrm{~kg}$ de peso vivo, verificaram, respectivamente, a composição de músculo, gordura e osso da perna de 0,900, 0,222 e 0,242 kg; do lombo, de 0,539,

Tabela 2 - Peso, em $\mathrm{kg}$, dos cortes comerciais de acordo com o tratamento e a raça Table 2 - Weight, in $\mathrm{kg}$, of the commercial cuts in agreement with the treatment and breed

\begin{tabular}{|c|c|c|c|c|c|}
\hline & \multicolumn{3}{|c|}{$\begin{array}{c}\text { Tratamentos } \\
\text { Treatments }\end{array}$} & \multicolumn{2}{|c|}{$\begin{array}{l}\text { Raças } \\
\text { Breeds }\end{array}$} \\
\hline & $\begin{array}{c}\text { T1-Controle } \\
\text { T1-Control }\end{array}$ & $\begin{array}{l}\text { T2 - Biju } \\
T 2-B i j u\end{array}$ & $\begin{array}{l}\text { T3 - DPS } \\
T 3-D S W\end{array}$ & Santa Inês & Bergamácia \\
\hline $\begin{array}{l}\text { Paleta } \\
\text { Whole should }\end{array}$ & 1,76 & 1,64 & 1,75 & 1,67 & 1,78 \\
\hline $\begin{array}{l}\text { Pernil } \\
\text { Ham }\end{array}$ & 3,24 & 2,90 & 3,26 & 3,08 & 3,25 \\
\hline $\begin{array}{l}\text { Lombo } \\
\text { Loin }\end{array}$ & 0,96 & 0,90 & 0,90 & 0,91 & 0,94 \\
\hline $\begin{array}{l}\text { Costela } \\
\text { Rib }\end{array}$ & 1,98 & 1,92 & 1,84 & 1,82 & 2,02 \\
\hline
\end{tabular}

\section{R. Bras. Zootec., v.31, n.3, p.1459-1468, 2002 (suplemento)}


Tabela 3 - Peso, em kg, de músculo, gordura e osso dos cortes comerciais em função dos tratamentos e da raça Table 3 - Weight, in $\mathrm{kg}$, of muscle, fat and bone of commercial cuts in function of the treatments and breed

\begin{tabular}{|c|c|c|c|c|}
\hline \multicolumn{3}{|c|}{$\begin{array}{c}\text { Tratamentos } \\
\text { Treatments }\end{array}$} & \multicolumn{2}{|c|}{$\begin{array}{l}\text { Raças } \\
\text { Breeds }\end{array}$} \\
\hline $\begin{array}{l}\text { T1-Controle } \\
\text { T1 - Control }\end{array}$ & $\begin{array}{l}\text { T2 - Biju } \\
T 2-B i j u\end{array}$ & $\begin{array}{l}\text { T3 - DPS } \\
T 3-D S W\end{array}$ & Santa Inês & Bergamácia \\
\hline
\end{tabular}

\begin{tabular}{|c|c|c|c|c|c|}
\hline \multicolumn{6}{|l|}{$\begin{array}{l}\text { Paleta } \\
\text { Whole should }\end{array}$} \\
\hline $\begin{array}{l}\text { Whole should } \\
\text { Músculo }\end{array}$ & 1,057 & 0,934 & 1,001 & 1,018 & 0,989 \\
\hline $\begin{array}{l}\text { Gordura } \\
\text { Fat }\end{array}$ & 0,384 & 0,398 & 0,403 & 0,330 & 0,467 \\
\hline $\begin{array}{l}\text { Osso } \\
\text { Bone } \\
\text { Pernil } \\
\text { Ham }\end{array}$ & 0,261 & 0,238 & 0,240 & 0,249 & 0,245 \\
\hline $\begin{array}{l}\text { Músculo } \\
\text { Muscle }\end{array}$ & 2,129 & 1,830 & 2,000 & $2,066 \mathrm{a}$ & $1,932 \mathrm{~b}$ \\
\hline $\begin{array}{l}\text { Gordura } \\
\text { Fat }\end{array}$ & 0,598 & 0,568 & 0,553 & 0,483 & 0,674 \\
\hline $\begin{array}{l}\text { Osso } \\
\text { Bone } \\
\text { Lombo }\end{array}$ & 0,437 & 0,400 & 0,446 & 0,436 & 0,424 \\
\hline $\begin{array}{l}\text { Loin } \\
\text { Músculo } \\
\text { Muscle }\end{array}$ & 0,436 & 0,348 & 0,397 & 0,411 & 0,384 \\
\hline Gordura & 0,138 & 0,114 & 0,113 & 0,106 & 0,141 \\
\hline $\begin{array}{l}\text { Osso } \\
\text { Bone } \\
\text { Costela } \\
\text { Rib }\end{array}$ & 0,140 & 0,304 & 0,128 & 0,216 & 0,138 \\
\hline $\begin{array}{l}\text { Músculo } \\
\text { Muscle }\end{array}$ & 0,966 & 0,884 & 0,891 & 0,921 & 0,912 \\
\hline $\begin{array}{l}\text { Gordura } \\
\text { Fat }\end{array}$ & 0,416 & 0,476 & 0,387 & 0,336 & 0,515 \\
\hline $\begin{array}{l}\text { Osso } \\
\text { Bone }\end{array}$ & 0,509 & 0,502 & 0,491 & 0,491 & 0,511 \\
\hline
\end{tabular}

Médias seguidas de letras diferentes diferem entre si, na linha, pelo teste de Tukey $(P<0,05)$. Means followed by the different letter differ among them, in the line, by the Tukey test $(P<0.05)$.

0,549 e $0,105 \mathrm{~kg}$ e da paleta, de $0,672,0,261$ e $0,224 \mathrm{~kg}$.

Os resultados obtidos neste experimento novamente foram mantidos quando as variáveis músculo, gordura e osso foram expressas em porcentagem do peso do próprio corte, como pode ser verificado na Tabela 4. Os cordeiros da raça Santa Inês apresentaram maior porcentagem de músculo no pernil, e os da raça Bergamácia, maior porcentagem de gordura na paleta. Possivelmente, a maior porcentagem de músculo em relação a gordura e ossos, nos cortes analisados, foi influenciada pela idade, pelo peso de abate e pelo tipo racial dos animais. Holloway et al. (1994), citados por Hopkins (1996), ao dissecarem a perna de cordeiros das raças Texel e Awassi, tam- bém verificaram maior quantidade de músculo e maior proporção de carne em relação ao osso. Já Lambuth et al. (1970) constataram que a composição da perna de cordeiros Hampshire x Blackface, abatidos com $45 \mathrm{~kg}$ de peso vivo, era de 62,23 e $14 \%$ para músculo, gordura e osso, respectivamente, sendo esses dados coerentes com os obtidos neste experimento.

Segundo Müller (1980), a área de olho de lombo isoladamente não representa uma alta correlação com a proporção de músculo na carcaça, porém, se utilizada em conjunto com outros parâmetros, pode auxiliar na avaliação do grau de rendimento dos cortes desossados na carcaça. Na Tabela 5 são apresentadas medidas da área do olho de lombo, 
Tabela 4 - Peso de músculo, gordura e osso de cortes comerciais expressos em porcentagem do peso do próprio corte, em função dos tratamentos e da raça

Table 4 - Weight of muscle, fat and bone of commercial cuts expressed in percentage of the weight of the own cut in function of the treatments and breed

\begin{tabular}{|c|c|c|c|c|c|}
\hline & \multicolumn{3}{|c|}{$\begin{array}{c}\text { Tratamentos } \\
\text { Treatments }\end{array}$} & \multicolumn{2}{|c|}{$\begin{array}{l}\text { Raças } \\
\text { Breeds }\end{array}$} \\
\hline & $\begin{array}{l}\text { T1-Controle } \\
\text { T1 - Control }\end{array}$ & $\begin{array}{l}\text { T2 - Biju } \\
T 2-B i j u\end{array}$ & $\begin{array}{l}\text { T3 - DPS } \\
T 3-D S W\end{array}$ & Santa Inês & Bergamácia \\
\hline Paleta & & & & & \\
\hline $\begin{array}{l}\text { Whole should } \\
\text { Músculo } \\
\text { Muscle }\end{array}$ & 61,537 & 57,529 & 57,875 & 61,069 & 56,982 \\
\hline $\begin{array}{l}\text { Gordura } \\
\text { Fat }\end{array}$ & 22,613 & 24,308 & 22,714 & $19,820^{\mathrm{a}}$ & $26,736^{\mathrm{b}}$ \\
\hline $\begin{array}{l}\text { Osso } \\
\text { Bone } \\
\text { Pernil } \\
\text { Ham }\end{array}$ & 15,189 & 14,623 & 14,036 & 14,945 & 14,249 \\
\hline $\begin{array}{l}\text { Músculo } \\
\text { Muscle }\end{array}$ & 69,766 & 63,905 & 64,425 & $70,005^{\mathrm{a}}$ & $62,090^{\mathrm{b}}$ \\
\hline $\begin{array}{l}\text { Gordura } \\
\text { Fat }\end{array}$ & 19,824 & 18,866 & 17,461 & 16,416 & 21,240 \\
\hline $\begin{array}{l}\text { Osso } \\
\text { Bone } \\
\text { Lombo } \\
\text { Loin }\end{array}$ & 14,291 & 14,052 & 14,331 & 14,707 & 13,727 \\
\hline $\begin{array}{l}\text { Músculo } \\
\text { Muscle }\end{array}$ & 43,000 & 42,007 & 47,477 & 46,944 & 41,548 \\
\hline $\begin{array}{l}\text { Gordura } \\
\text { Fat }\end{array}$ & 13,449 & 12,994 & 12,893 & 11,545 & 14,880 \\
\hline $\begin{array}{l}\text { Osso } \\
\text { Bone } \\
\text { Costela } \\
\text { Rib }\end{array}$ & 0,140 & 0,304 & 0,128 & 25,614 & 14,567 \\
\hline $\begin{array}{l}\text { Músculo } \\
\text { Muscle }\end{array}$ & 49,458 & 46,409 & 46,597 & 49,156 & 45,874 \\
\hline $\begin{array}{l}\text { Gordura } \\
\text { Fat }\end{array}$ & 20,534 & 24,240 & 19,822 & 17,698 & 25,191 \\
\hline $\begin{array}{l}\text { Osso } \\
\text { Bone }\end{array}$ & 26,024 & 26,061 & 26,318 & 26,028 & 25,987 \\
\hline
\end{tabular}

Médias seguidas de letras diferentes diferem entre si, na linha, pelo teste de Tukey $(P<0,05)$. Averages followed by the different letter differ among them, in the line, by the Tukey test $(P<0.05)$.

expressa em milímetros quadrados, da largura e do comprimento, em centímetros, do músculo longissimus dorsi. Houve influência da dietas sobre a área de olho de lombo, de modo que a dieta controle propiciou maior desenvolvimento da área de lombo que a dieta que continha dejetos de suínos na forma de biju; no entanto, esta foi estatisticamente semelhante à dieta com dejetos na forma de DPS; e nesta variável não houve diferença entre os dejetos. Os cordeiros da raça Santa Inês também apresentaram maior desenvolvimento da área de olho de lombo, da largura e do comprimento. Já as dietas não influenciaram nas variáveis largura e comprimento da área de olho de lombo.
Carvalho et al . (1980), trabalhando com cordeiros das raças Corriedale, Ideal, Romney Marsh e cruzas, com 120 dias de idade e abatidos com cerca de $21 \mathrm{~kg}$, verificaram área de olho de lombo inferior à deste trabalho, com $752 \mathrm{~mm}^{2}$; e Müller et al. (1976), com cordeiros do mesmo tipo racial e abatidos com 120 dias de idade verificaram uma área de olho de lombo de $790 \mathrm{~mm}^{2}$. Loose et al. (1981) também constataram valores inferiores para a área de olho de lombo de $888 \mathrm{~mm}^{2}$ e profundidade e largura do olho de lombo de 2,30 e $4,88 \mathrm{~cm}$, respectivamente, em carcaças de cordeiros castrados das raças Ideal e cruzas Ideal $\mathrm{x}$ Texel, abatidos aos 84 dias de idade e criados em 
Tabela 5 - Medidas da área do olho de lombo, expressa em milímetros quadrados, e da largura e do comprimento, em centímetros, do músculo Longissimus dorsi

Table 5 - Measures of the loin eye area, expressed in millimeters square, of the width and length, in centimeters, of the muscle Longissimus dorsi

\begin{tabular}{|c|c|c|c|c|c|}
\hline & \multicolumn{3}{|c|}{$\begin{array}{c}\text { Tratamentos } \\
\text { Treatments }\end{array}$} & \multicolumn{2}{|c|}{$\begin{array}{l}\text { Raças } \\
\text { Breeds }\end{array}$} \\
\hline & $\begin{array}{l}\text { T1- Controle } \\
\text { T1 - Control }\end{array}$ & $\begin{array}{l}\text { T2 - Biju } \\
T 2-B i j u\end{array}$ & $\begin{array}{l}\text { T3 - DPS } \\
T 3-D S W\end{array}$ & Santa Inês & Bergamácia \\
\hline $\begin{array}{l}\text { Área olho lombo } \\
\text { Area loin eye }\end{array}$ & $1.852,10^{\mathrm{a}}$ & $1.450,80^{\mathrm{b}}$ & $1.616,30^{\mathrm{ab}}$ & $1.814,94^{\mathrm{a}}$ & $1.487,08^{\mathrm{b}}$ \\
\hline $\begin{array}{l}\text { Largura } \\
\text { Width }\end{array}$ & 3,71 & 3,32 & 3,45 & 3,76 a & $3,32 \mathrm{~b}$ \\
\hline $\begin{array}{l}\text { Comprimento } \\
\text { Length }\end{array}$ & 6,16 & 5,61 & 5,66 & $6,00 \mathrm{a}$ & $5,67 \mathrm{~b}$ \\
\hline
\end{tabular}

Médias seguidas de letras diferentes diferem entre si, na linha, pelo teste de Tukey $(P<0,05)$.

Averages followed by the different letter differ among them, in the line, by the Tukey test $(P<.05)$.

regime extensivo. Já Bona Filho et al. (1994), trabalhando com cordeiros mestiços abatidos aos 139 dias de idade e alimentados parcialmente com níveis crescentes de farinha de peixe, verificaram $1.326 \mathrm{~mm}^{2}$ de área de olho de lombo. Valores de $1.340 \mathrm{~mm}^{2}$ de área de olho de lombo, $6,0 \mathrm{~cm}$ de comprimento e $2,8 \mathrm{~cm}$ de profundidade do músculo Longissimus dorsi, foram observados por Hopkins (1996), ao abater cordeiros cruzados e criptorquidas. Também foram encontradas área de $1.580 \mathrm{~mm}^{2}$ (Lambuth et al., 1970) e cerca de $1.800 \mathrm{~mm}^{2}$ de área como média para cordeiros Suffolk e Rambouillet (Crouse et al., 1981).

$\mathrm{Na}$ Tabela 6 estão descritos os pesos, em kg, do aparelho digestivo e os pesos individuais dos órgãos do aparelho digestivo, de acordo com o tratamento e a raça. No entanto, não foi verificada nenhuma influência dos dejetos de suínos ou das raças sobre o peso do aparelho digestivo ou no peso individual do retículo/rúmen, do omaso, do abomaso, do intestino delgado e do intestino grosso. Resultados semelhantes foram descritos por Kouakou et al. (1997) ao abaterem cordeiros Rambouillet x Dorset com 120 dias de idade; valores inferiores foram verificados por Butterfield et al. (1983), ao abaterem cordeiros Merino Australiano.

Os resultados também se mantiveram quando o aparelho digestivo e os órgãos internos foram expressos como porcentagem do peso do próprio aparelho digestivo, não havendo diferenças entre os tratamentos e as raças para as variáveis estudadas, com exceção do intestino delgado, onde a dieta controle

Tabela 6 - Peso, em kg, do aparelho digestivo e dos órgãos do aparelho digestivo de acordo com o tratamento e a raça Table 6 - Weigh, in $\mathrm{kg}$, of the digestive system and organs of the digestive system in agreement with the treatment and breed

\begin{tabular}{|c|c|c|c|c|c|}
\hline & \multicolumn{3}{|c|}{$\begin{array}{c}\text { Tratamentos } \\
\text { Treatments }\end{array}$} & \multicolumn{2}{|c|}{$\begin{array}{l}\text { Raças } \\
\text { Breeds }\end{array}$} \\
\hline & $\begin{array}{c}\text { T1-Controle } \\
\text { T1-Control }\end{array}$ & $\begin{array}{l}\mathrm{T} 2-\mathrm{Biju} \\
T 2-B i j u\end{array}$ & $\begin{array}{l}\text { T3 - DPS } \\
T 3-D S W\end{array}$ & Bergamácia & Santa Inês \\
\hline $\begin{array}{l}\text { Aparelho digestivo } \\
\text { Digestive system }\end{array}$ & 1,957 & 1,842 & 1,944 & 1,882 & 1,958 \\
\hline $\begin{array}{l}\text { Retículo/rúmen } \\
\text { Reticulum/rumen }\end{array}$ & 0,664 & 0,668 & 0,715 & 0,676 & 0,688 \\
\hline $\begin{array}{l}\text { Omaso } \\
\text { Omasum }\end{array}$ & 0,082 & 0,081 & 0,091 & 0,084 & 0,086 \\
\hline $\begin{array}{l}\text { Abomaso } \\
\text { Abomasum }\end{array}$ & 0,129 & 0,147 & 0,135 & 0,138 & 0,136 \\
\hline $\begin{array}{l}\text { Intestino delgado } \\
\text { Small intestine }\end{array}$ & 0,670 & 0,581 & 0,519 & 0,579 & 0,602 \\
\hline $\begin{array}{l}\text { Intestino grosso } \\
\text { Large intestine }\end{array}$ & 0,354 & 0,374 & 0,466 & 0,362 & 0,434 \\
\hline
\end{tabular}


proporcionou maior desenvolvimento deste órgão em relação à dieta que continha dejetos de suínos na forma de DPS (Tabela 7).

$\mathrm{Na}$ Tabela 8 são apresentados os pesos, em kg, de alguns órgãos internos (traquéia, pulmão, coração, fígado e baço) e da gordura visceral (omental e mesentérica). Não se verificou nenhum efeito das dietas ou das raças sobre o peso desses órgãos, sendo apenas verificado maior peso da traquéia para os cordeiros da raça Santa Inês. Resultados semelhantes para pulmão e baço - 0,421 e $0,061 \mathrm{~kg}$, respecti- vamente - foram descritos por Kouakou et al. (1997); todavia, o peso do fígado foi inferior e o do coração superior - 0,454 e $0,179 \mathrm{~kg}$, respectivamente - aos do presente experimento. Jardim et al. (1981), ao trabalharem com cordeiros Ideal e cruzas Ideal x Texel, abatidos aos 86 dias de idade, encontraram pesos de pulmão, fígado e coração inferiores ao deste experimento. Do mesmo modo, Kabbali et al. (1992), ao trabalharem com cordeiros abatidos com $30 \mathrm{~kg}$ de peso vivo, também verificaram pesos inferiores para pulmão, fígado, baço e gordura mesentérica. Já

Tabela 7 - Órgãos do aparelho digestivo, expresso como porcentagem do peso do aparelho digestivo, em função dos tratamentos e das raças

Table 7 - Organs of the digestive system, expressed as percentage of the weight of digestive system, in function of treatments and breed

\begin{tabular}{|c|c|c|c|c|c|}
\hline & \multicolumn{3}{|c|}{$\begin{array}{c}\text { Tratamentos } \\
\text { Treatments }\end{array}$} & \multicolumn{2}{|c|}{$\begin{array}{l}\text { Raças } \\
\text { Breeds }\end{array}$} \\
\hline & $\begin{array}{c}\text { T1-Controle } \\
\text { T1-Control }\end{array}$ & $\begin{array}{l}\text { T2 - Biju } \\
T 2-B i j u\end{array}$ & $\begin{array}{l}\text { T3 - DPS } \\
T 3-D S W\end{array}$ & Bergamácia & Santa Inês \\
\hline $\begin{array}{l}\text { Retículo/rúmen } \\
\text { Reticulum/rumen }\end{array}$ & 36,230 & 36,490 & 37,661 & 38,120 & 35,661 \\
\hline $\begin{array}{l}\text { Omaso } \\
\text { Omasum }\end{array}$ & 3,954 & 4,162 & 4,570 & 4,088 & 4,369 \\
\hline $\begin{array}{l}\text { Abomaso } \\
\text { Abomasum }\end{array}$ & 6,901 & 8,033 & 7,054 & 7,633 & 6,915 \\
\hline $\begin{array}{l}\text { Intestino delgado } \\
\text { Small Intestine }\end{array}$ & $31,785^{\mathrm{a}}$ & $31,264^{\mathrm{ab}}$ & $26,036^{\mathrm{b}}$ & 27,892 & 31,004 \\
\hline $\begin{array}{l}\text { Intestino grosso } \\
\text { Large Intestine }\end{array}$ & 21,128 & 20,051 & 24,678 & 22,266 & 22,051 \\
\hline
\end{tabular}

${ }^{1}$ Médias seguidas de letras diferentes diferem entre si pelo teste de Tukey $(\mathrm{P}<0,05)$.

${ }^{1}$ Means followed by the different letters differ by the Tukey test $(P<.05)$.

Tabela 8 - Peso, em kg, de alguns órgãos internos e da gordura (omental e mesentérica) de acordo com o tratamento e a raça

Table 8 - Weigh, in $\mathrm{kg}$, of some internal organs and of the fat (omental and mesentérica) in agreement with the treatment and breed

\begin{tabular}{|c|c|c|c|c|c|}
\hline & \multicolumn{3}{|c|}{$\begin{array}{c}\text { Tratamentos } \\
\text { Treatments }\end{array}$} & \multicolumn{2}{|c|}{$\begin{array}{l}\text { Raças } \\
\text { Breeds }\end{array}$} \\
\hline & $\begin{array}{c}\text { T1-Controle } \\
\text { T1-Control }\end{array}$ & $\begin{array}{l}\mathrm{T} 2-\mathrm{Biju} \\
T 2-B i j u\end{array}$ & $\begin{array}{l}\text { T3 - DPS } \\
T 3-D S W\end{array}$ & Bergamácia & Santa Inês \\
\hline $\begin{array}{l}\text { Traquéia } \\
\text { Windpipe }\end{array}$ & 0,487 & 0,594 & 0,585 & $0,489^{b}$ & $0,621^{\mathrm{a}}$ \\
\hline $\begin{array}{l}\text { Pulmão } \\
\text { Lung }\end{array}$ & 0,426 & 0,441 & 0,460 & 0,440 & 0,445 \\
\hline $\begin{array}{l}\text { Coração } \\
\text { Heart }\end{array}$ & 0,139 & 0,141 & 0,143 & 0,131 & 0,151 \\
\hline $\begin{array}{l}\text { Fígado } \\
\text { Liver }\end{array}$ & 0,680 & 0,594 & 0,648 & 0,611 & 0,671 \\
\hline $\begin{array}{l}\text { Baço } \\
\text { Spleen }\end{array}$ & 0,066 & 0,073 & 0,071 & 0,068 & 0,072 \\
\hline $\begin{array}{l}\text { Gordura visceral } \\
\text { Visceral fat }\end{array}$ & 2,060 & 2,233 & 1,998 & 2,107 & 2,087 \\
\hline
\end{tabular}

\footnotetext{
${ }^{1}$ Médias seguidas de letras diferentes diferem entre si pelo teste de Tukey $(P<0,05)$.
}

${ }^{1}$ Means followed by the different letters differ by the Tukey test $(P<.05)$.

\section{R. Bras. Zootec., v.31, n.3, p.1459-1468, 2002 (suplemento)}


Butterfield et al. (1983) constataram pesos superiores aos do presente trabalho para o fígado, baço, coração e pulmão e inferior para a traquéia.

Os resultados foram novamente semelhantes quando os órgãos internos e a gordura visceral foram expressos como porcentagem do peso vazio (Tabela 9), sendo determinada maior porcentagem de traquéia para os cordeiros da raça Santa Inês. Também não houve nenhuma influência dos dejetos de suínos ou das raças sobre os componentes corporais externos, como a cabeça e os pés/canela. Todavia, os cordeiros da raça Bergamácia apresentaram maior proporção de pele que os cordeiros da raça Santa Inês, por serem lanados. Carvalho et al. (1980), trabalhando com cordeiros das raças Corriedale, Ideal, Romney Marsh e cruzas, com 120 dias de idade e abatidos com cerca de $21 \mathrm{~kg}$, verificaram que o peso médio da pele mais lã era de 2,1 kg. Os pesos médios encontrados por Jardim et al. (1981) para pele, patas e cabeça foram 1,$48 ; 0,40$ e $0,78 \mathrm{~kg}$, respectivamente. Latif \& Owen (1980) constataram que os pesos da cabeça e dos pés eram de 1,64 e 0,80 kg, respectivamente, sendo esses valores médios para cordeiros das raças Suffolk e Texel, abatidos com cerca de $36 \mathrm{~kg}$ de peso vivo.

De acordo com Alcalde Aldea \& Sierra Alfranca (1993), o tamanho da cabeça dos ovinos poderá influenciar o aproveitamento do animal, uma vez que nos machos o desenvolvimento cefálico é uma característica sexual secundária. Portanto, quanto mais velho for abatido o animal, maior será o peso da cabeça. Esses autores, ao abaterem cordeiros Merino Precoz x Merino com 24,6 kg, encontraram 1,45 e $2,14 \mathrm{~kg}$; e 6,83 e $10,12 \%$ do peso vazio, para a cabeça e pele, respectivamente, sendo esses valores superiores aos encontrados neste experimento. Possivelmente essa semelhança encontrada na maioria das variáveis entre os cordeiros das raças Bergamácia e Santa Inês se deva à pequena seleção e melhoramento genético que estas raças vêm sofrendo ao longo dos anos, já que estes animais vêm sendo criados quase que exclusivamente sob regime extensivo, e à semelhança genética destas raças, já que a raça Santa Inês foi selecionada a partir de cruzamentos entre a raça Bergamácia e a raça deslanada Morada Nova.

Tabela 9 - Órgãos internos, gordura (omental e mesentérica), cabeça, pés/canelas e pele, expressos em \% do peso vazio, de acordo com o tratamento e a raça

Table 9 - Internal organs, fat (omental and mesenteric), head, foot/shin and skin, expressed in \% of the empty weight, in agreement with the treatment and breed

\begin{tabular}{|c|c|c|c|c|c|}
\hline & \multicolumn{3}{|c|}{$\begin{array}{c}\text { Tratamentos } \\
\text { Treatments }\end{array}$} & \multicolumn{2}{|c|}{$\begin{array}{l}\text { Raças } \\
\text { Breeds }\end{array}$} \\
\hline & $\begin{array}{l}\text { T1-Controle } \\
\text { T1-Control }\end{array}$ & $\begin{array}{l}\mathrm{T} 2-\mathrm{Biju} \\
T 2-B i j u\end{array}$ & $\begin{array}{l}\text { T3 - DPS } \\
T 3-D S W\end{array}$ & Bergamácia & Santa Inês \\
\hline $\begin{array}{l}\text { Traquéia } \\
\text { Windpipe }\end{array}$ & 1,477 & 1,658 & 1,596 & $1,210^{\mathrm{b}}$ & $1,577^{\mathrm{a}}$ \\
\hline $\begin{array}{l}\text { Pulmão } \\
\text { Lung }\end{array}$ & 1,074 & 1,165 & 1,173 & 1,128 & 1,139 \\
\hline $\begin{array}{l}\text { Coração } \\
\text { Heart }\end{array}$ & 0,347 & 0,350 & 0,360 & 0,323 & 0,379 \\
\hline $\begin{array}{l}\text { Fígado } \\
\text { Liver }\end{array}$ & 1,680 & 1,497 & 1,630 & 1,500 & 1,715 \\
\hline $\begin{array}{l}\text { Gordura } \\
\text { Fat }\end{array}$ & 4,734 & 5,197 & 4,753 & 4,732 & 4,980 \\
\hline $\begin{array}{l}\text { Cabeça } \\
\text { Head }\end{array}$ & 5,708 & 5,592 & 6,441 & 5,734 & 6,140 \\
\hline $\begin{array}{l}\text { Pés/Canela } \\
\text { Foot/Shin }\end{array}$ & 2,767 & 2,823 & 2,698 & 2,710 & 2,799 \\
\hline $\begin{array}{l}\text { Pele } \\
\text { Skin }\end{array}$ & 8,168 & 7,613 & 8,485 & $9,406^{\mathrm{a}}$ & $6,998^{\mathrm{b}}$ \\
\hline
\end{tabular}

${ }_{1}^{1}$ Médias seguidas de letras diferentes diferem entre si pelo teste de Tukey $(P<0,05)$.

${ }^{1}$ Means followed by the different letters differ by the Tukey test $(P<.05)$. 


\section{Conclusões}

Entre raças não houve diferenças no peso dos cortes comerciais e nos componentes corporais externos. Contudo, os animais da raça Santa Inês apresentaram pernil e área de olho de lombo com maior proporção de músculo e maior peso de traquéia; já os da raça Bergamácia mostraram maior porcentagem de gordura na paleta e maior peso da pele.

Não houve influência das dietas nos cortes comerciais, nos órgãos internos do aparelho digestivo e nos componentes corporais externos, com exceção da área de olho de lombo e da proporção de intestino delgado, que foram superiores para os animais que receberam a dieta controle.

\section{Literatura Citada}

ALCALDE ALDEA, M.J.; SIERRA ALFRANCA, I. Acabado de corderos Merinos extremeños en cebadero: pesos, crecimientos, rendimientos y valor del quinto cuarto. Archivos de Zootecnia, v.42, n.157, p.161-172, 1993.

BONA FILHO, A.; OTTO,C.; LEME, M.C.J. et al. Ganho de peso e características de carcaça de cordeiros confinados e suplementados com diferentes níveis de farinha de peixe em substituição ao farelo de soja. Agrárias Curitiba, v.13, n.12, p.183-191, 1994.

BUTTERFIELD, R.M.; ZAMORA, J.; JAMES, A.M. et al. Changes in body composition relative to weight and maturity in large and small strains of Australian Merino rams. 3. Body organs. Animal Production, v.36, p.461-470, 1983.

CARVALHO, J.B.P.; PEDROSO, J.R.; FIGUEIRÓ, P.R.P. et al. Alguns fatores que afetam o rendimento da carne ovina. Revista Centro Ciências Rurais, v.10, n.2, p.95-104, 1980.

CROUSE, J.D.; BUSBOOM, J.R.; FIELD, R.A. et al. The effects of breed, diet, sex, location and slaughter weight on lamb growth, carcass composition and meat flavor. Journal of Animal Science, v.53, n.2, p.376-386, 1981.

FIGUEIRÓ, P.R.P. Rendimento de carcaça em ovinos no Rio Grande do Sul. In: JORNADA TÉCNICA DE PRODUÇÃO OVINA NO RIO GRANDE DO SUL, 1979, Bagé. Anais ... Bagé: EMBRAPA - EMATER RS - ARCO - SEAGRI, 1979. p.65-78.

MAYNARD, L.A; LOOSLI, J.K.; HINTZ, H.F. et al. Nutrição animal. Rio de Janeiro: Freitas Bastos, 1984. p.736.

HOPKINS, D.L. The relationship between muscularity, muscle:bone ratio and cut dimensions in male and female lamb carcasses and the measurement of muscularity using image analysis. Meat Science, v.44, n.4, p.307-317, 1996.

JARDIM, P.O.C.; OSÓRIO, J.C.S.; SILVEIRA, O.A. et al. Componentes do peso corporal de cordeiros Ideal e cruzas Ideal x Texel. In: REUNIÃO ANUAL DA SOCIEDADE BRASILEIRA DE ZOOTECNIA, 18., 1981, Goiânia. Anais... Goiânia: Sociedade Brasileira de Zootecnia, 1981. p.397.

KABBALI, A.; JOHNSON, W.L.; JOHNSON, D.W. et al. Effects of compensatory growth on some body component weights and on carcass and noncarcass composition of growing lambs. Journal of Animal Science, v.70, p.2852-2858, 1992.
KHANDEKAR, V.N.; GOLDSTONE, C.L.; McMANUS, W.R. Some indices of the carcass composition of Dorset Horn top cross lambs.1. Measurements on the live body and carcass, the composition of sample joints and their relationship to carcass composition. Journal of Agricultural Science, v.65, p.147-154, 1965.

KIRTON, A.H.; CARTER, A.H.; CLARKE, J.N. et al. A comparison between 15 ram breeds for export lamb production. 1- Live weights, body components, carcass measurements and compositions. New Zealand Journal Agricultural Research, Hamilton, v.38, p.347-360, 1995.

KOUAKOU, B.; GOETSCH, A.L.; PATIL, A.R. et al. Visceral organ mass in wethers consuming diets with different forages and grain levels. Livestock Production Science, v.47, p.125$137,1997$.

LAMBUTH, T.R.; KEMP, J.D.; GLIMP, H.A. Effect of rate of gain and slaughter weight on lamb carcass composition. Journal of Animal Science, v.30, n.27, p.27-35, 1970.

LATIF, M.G.A.; OWEN, E. A note on the growth performance and carcass composition of Texel and Suffolk-sired lambs in an intensive feeding system. Animal Production, v.30, p.311-314, 1980.

LOOSE, E.L.; JARDIM, P.O.C.; OSÓRIO, J.C.S. et al. Estudo comparativo de carcaças de cordeiros Ideal com cruzas Ideal $x$ Texel. In: REUNIÃO ANUAL DA SOCIEDADE BRASILEIRA DE ZOOTECNIA, 18., 1981, Goiânia. Anais... Goiânia: Sociedade Brasileira de Zootecnia, 1981. p.396.

MÜLLER, L. Normas para avaliação de carcaças e concurso de carcaças de novilhos. Santa Maria: Universidade Federal de Santa Maria, 1980. p.31.

MÜLLER, L.; FIGUEIRÓ, P.; HALL, G. Relação entre o peso de carcaça e o rendimento da perna em cordeiros. In: REUNIÃO ANUAL DA SOCIEDADE BRASILEIRA DE ZOOTECNIA, 1976, Salvador. Anais ... Salvador: Sociedade Brasileira de Zootecnia, 1976. p.84-85.

MURPHY, T.A.; LOERCH, S.C.; McCLURE, K.E. et al. Effects of restricted feeding on growth performance and carcass composition of lambs. Journal of Animal Science, v.72, p.3131-3137, 1994.

OLIVEIRA, P.A.V. Manual de manejo e utilização dos dejetos de suínos. Concórdia: EMBRAPA-CNPSA, 1993. p.188. (Documentos, n. 27)

RODRIGUES, A.; PÉREZ, J.R.O.; OLIVEIRA, M.V.M. Desempenho de cordeiros Santa Inês e Bergamácia, terminados em confinamento, usando dejetos de suínos como parte da dieta. In: REUNIÃO ANUAL DA SOCIEDADE BRASILEIRA DE ZOOTECNIA, 33., 1996, Fortaleza. Anais ... Fortaleza: Sociedade Brasileira de Zootecnia, 1996. p.208-210.

SAS INSTITUTE. Statistical Analysis System. User's Guide. 4.ed. Cary: 1990. 890p. 